\title{
Correction to: Novel, emerging and provisional renal entities: the Genitourinary Pathology Society (GUPS) update on renal neoplasia
}

Kiril Trpkov 1 - Sean R. Williamson (1) - Anthony J. Gill • Adebowale J. Adeniran • Abbas Agaimy

Reza Alaghehbandan - Mahul B. Amin - Pedram Argani - Ying-Bei Chen 1 - Liang Cheng 1 - Jonathan I. Epstein • John C. Cheville - Eva Comperat · Isabela Werneck da Cunha (1) - Jennifer B. Gordetsky (10) Sounak Gupta • Huiying He - Michelle S. Hirsch (D) Peter A. Humphrey - Payal Kapur - Fumiyoshi Kojima - Jose I. Lopez (1)

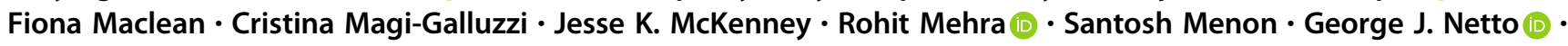
Christopher G. Przybycin - Priya Rao - Qiu Rao - Victor E. Reuter - Rola M. Saleeb - Rajal B. Shah • Steven C. Smith (1) - Satish Tickoo - Maria S. Tretiakova (1) - Lawrence True • Virginie Verkarre - Sara E. Wobker • Ming Zhou • Ondrej Hes

Published online: 16 March 2021

(c) The Author(s), under exclusive licence to United States \& Canadian Academy of Pathology 2021

Correction to: Modern Pathology https://doi.org/10.1038/s41379-021-00737-6
The original version of this article unfortunately contained a mistake. There was a typo in the heading of Fig. 5. The word "lymoma" should be "lymphoma". The original article has been corrected. 